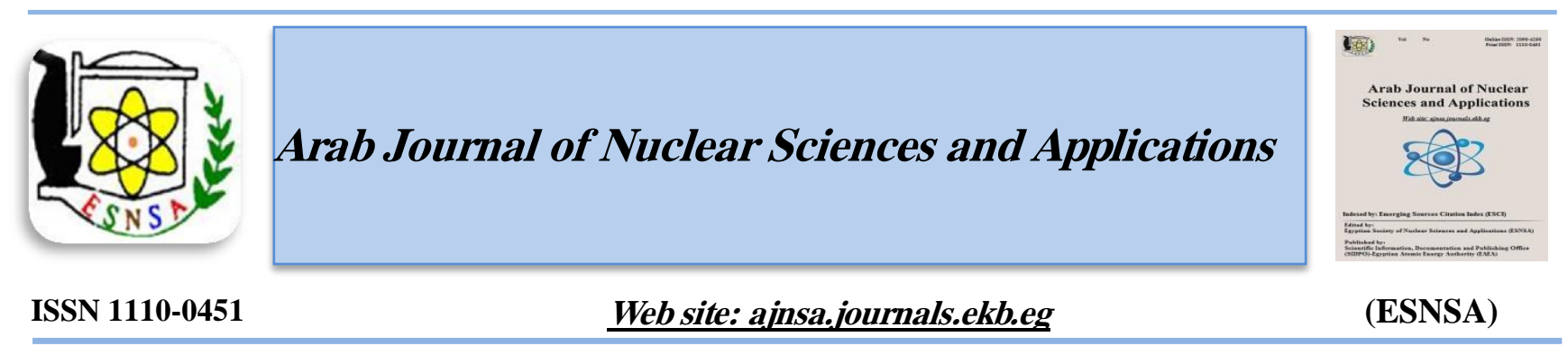

\title{
Comparative Chemical Studies Between Fixed Bed and Batch Dynamic Ion Exchange Techniques for Extraction of Uranium
}

\author{
M.M. Abdel Aal and A.A. AbdelSamad \\ Nuclear Materials Authority, Cairo, Egypt
}

\begin{abstract}
Received $6^{\text {th }}$ Aug. 2018 Leach solution of uranium from different resources was collected and characterized. Batch method and Accepted $28^{\text {th }}$ Mar. 2019 fixed column recovery of uranium from this leach liquor were carried out. Different parameters affecting the extraction of uranium from its solution using anion exchange resin were studied by using both Batch method and fixed column techniques. Applying the batch method, about $90 \%$ of uranium was extracted from its solution within 15 minutes. On the other hand, utilizing the fixed column technique, extraction of $93 \%$ of the uranium was possible using Amberlite IRA400, but this process takes a long time. Under the present conditions, it found that recovery of uranium from small volumes of these leach solution, it preferred to carry out using batch method.
\end{abstract}

Keywords: Fixed bed, Batch method ion exchange technique, Uranium extraction

\section{Introduction}

Ion-exchange sorbents usually contain cationic or anionic functional groups that can exchange uranium from its solutions. Strong and weak sites refer to the fact that strong sites are always present as ion-exchange sites at any $\mathrm{pH}$ value [1], while weak sites are only ion-exchange sites at $\mathrm{pH}$ values greater or less than the $\mathrm{pK}$. Strong sites are sulfonic acid groups (cation-exchange) and quaternary amines (anion-exchange), while weak sites consist of carboxylic acid groups (cationexchange) or primary, secondary and tertiary amines (anion-exchange) [2]. The aim of most of the research works in the field of ion exchange is to enhance functional properties related to selectivity, capacity and exchange rate, which have direct impact on the applicability of the resins. From a selectivity point of view [3], chelating resins are well known of their high selectivity as their functional groups, must contain one or more donor atoms to form coordination bonds. These materials have been employed successfully by different researchers over a wide range of separation processes [4]. They have been utilized in more difficult tasks like isotope separation, removal of uranium and organic matters from seawater [5]. Organic ion-exchangers have great applications in the field of analytical chemistry [6]. A lot of attention has been paid for selective separation of certain metal ions in the presence of interfering ions at moderate conditions [7].

The ion exchange process is based on the ability of anion exchange resins to extract uranium selectively from sulfuric acid or carbonate leach solutions $[8,9]$. After the uranium is concentrated in the resin, it is displaced and eluted by a suitable salt solution to obtain highly concentrated and relatively pure uranium liquor [10]. This liquor is, then, treated with alkaline precipitants to yield a high-grade uranium cake.

The main advantages of this process over direct precipitation are that:

i- It reduces the volume of solution that must be chemically treated to recover uranium

Corresponding author:fekragp@gmail.com

DOI: 10.21608/ajnsa.2019.4521.1108

(C) Scientific Information, Documentation and Publishing Office (SIDPO)-EAEA 
ii- It provides for quantitative recovery of uranium from solution

iii- It produces a uranium cake of high purity

The ion exchange process involves the ability of hexavalent uranium as uranyl ion, $\mathrm{UO} 22+$, to form anionic complexes with sulfate ions, SO42- , or carbonate ions, CO32- [11, 12]. In acid sulfate media, the uranyl ion exists in dynamic equilibrium with its sulfate complexes:

$$
\mathrm{UO}_{2}{ }^{2+}+\mathrm{nSO}_{4}{ }^{2-} \leftrightarrow \mathrm{UO}_{2}\left(\mathrm{SO}_{4}\right)_{\mathrm{n}}{ }^{2-2 \mathrm{n}}
$$

Where $\mathrm{n}=1,2$, or 3

In alkaline carbonate solutions, the uranyl ion is complexed strongly with the carbonate to form a well-defined species:

$$
\mathrm{UO}_{2}{ }^{2+}+3 \mathrm{CO}_{3}{ }^{2-} \leftrightarrow \mathrm{UO}_{2}\left(\mathrm{CO}_{3}\right)_{3}{ }^{4-}
$$

The ion exchange process is based on adsorbing these anionic complexes selectively and quantitatively on an anionic exchange resin as illustrated in the following reactions, where $\mathrm{R}+$ represents the fixed ion exchange sites of the resin [13].

\section{$4 \mathrm{R}^{+} \mathrm{X}^{-}+\mathrm{UO}_{2}\left(\mathrm{SO}_{4}\right)_{3}{ }^{-4} \leftrightarrow(\mathrm{R})_{4} \mathrm{UO}_{2}\left(\mathrm{SO}_{4}\right)_{3}+4 \mathrm{X}^{-}$ (3)$$
4 \mathrm{R}^{+} \mathrm{X}^{-}+\mathrm{UO}_{2}\left(\mathrm{CO}_{3}\right)_{3}^{-4} \leftrightarrow(\mathrm{R})_{4} \mathrm{UO}_{2}\left(\mathrm{CO}_{3}\right)_{3}+
$$$$
4 \mathrm{X}^{-} \text {(4) }
$$

Where $\mathrm{X}-\mathrm{NO}_{3}{ }^{-}$or $\mathrm{Cl}^{-}$. The above reactions are reversible, and the uranium may be desorbed or eluted from the resin by shifting the reactions to the left. This is usually accomplished with aqueous solutions containing either nitrate or chloride salts. The resins used in the extraction of uranium are mentioned in a previous study [14]:

i- The anion exchange resins which contain either weakly basic $\left(-\mathrm{NH}_{2} \cdot \mathrm{HCl}\right)$ or strongly basic $\left(-\mathrm{N}\left(\mathrm{CH}_{3}\right)_{3}{ }^{+} \mathrm{Cl}^{-}\right)$functional groups, where the chloride ions are capable of exchanging with other anions. In uranium recovery, only anion exchange resins possessing strongly basic quaternary ammonium groups are currently of importance.

The main variable in the design of an ion-exchange plant is the configuration of the resin, while it reacts with the aqueous feed solution [15]. In the past, fixed beds were considered for most ionexchange processes, whereas modern technology allows the designer to choose between fixed beds, moving packed beds, fluidized beds, and stirred tanks. The amount of suspended solids in the feed solution determines which of these possibilities are feasible. Packed beds of resin act as efficient filters and rapidly blocked if suspended solids are present, whereas fluidized beds can handle up to several hundred parts per million of the fine solids[16]. Stirred tanks can handle slurries containing up to $20 \mathrm{wt} . \%$ solids provided that no particles are larger than the resin beads[17]. The size of the plant is a further factor that may lead the designer to consider other options besides the conventional fixed bed. A very small plant may be comprised of overdesigned fixed beds to simplify operation and require no instrumentation[18]. The above mentioned factors, combined with the fact that high flow rates obtainable in packed beds give faster reaction rates, have led to the development of present-day plants. In general, clear dilute solutions are treated in fixed or moving packed beds while turbid effluents and ore slurries are handled in fluidized beds or stirred tanks.

Ion-exchange through fixed beds in columns encounters some defects which could be defined as needing long time for performance, being of very low rates of liquor feeding for adsorption and elution, needing large volumes of liquor to reach break point on breakthrough curve, necessitating leakage of the adsorbed metal from one column to multiply the extraction columns reaching 3 or 4 . On the other hand, the use of continuous ion exchange may significantly reduce the capital cost of a large plant [19].

The aim of this work is to invistegate the recovery of uranium from acidic waste solutions obtained from Yellow cake purification project [project 8] in Nuclear Material Authority (NMA) by the ion exchange Amberlite IRA 400 using two models, fixed bed and dynamic (batch mixing). A comparison of the data obtained was given and discused. Based on these comparative studies, a recommondation for the optimum ion exchange system is given.

\section{Experimental details}

Resin

A commercial strong base resin, Rohm and Haas, IRA $400\left(\mathrm{Cl}^{-}\right)$, consisting of a polystyrenic matrix, specially developed for the extraction of uranium 
and with a capacity of $1.0 \mathrm{~g}$. equiv/L, particle size 20-25 mesh, was selected for this study.

\section{Sample}

The industrial effluent was supplied by project 8 (NMA). The solution was collected from all batches used in the purification of uranium which was supplied from different locations and projects of the Nuclear Material Authority [20]. All these solution mixed together, volume reduction by precipitation of all components takes place using caustic soda, then dissolved again in $0.5 \mathrm{M}$ sulphuric acid, to convert the medium into sulphate form. Chemical analyses of the sample after filtration for the removal of solid fragments are shown in Table (1).

EDX procedure has analyzed qualitatively the working sample and indicated the presence of Si with a high value. Also, $\mathrm{Al}, \mathrm{K}, \mathrm{O}$ peaks were significantly observed in addition to the presence of $\mathrm{Na}, \mathrm{S}, \mathrm{U}, \mathrm{Fe}, \mathrm{Cu}, \mathrm{Zn}$ as shown in Fig. (1). The measured $\mathrm{x}$-ray energy dispersive spectra are automatically compared against a database of known spectra and a mineral or phase name is assigned to each measurement point [21].

\section{Uranium content determination}

Uranium analysis was spectrophotometrically determined by the Arsenazo-III method [21]: The absorbency of the formed uranium complex was measured at $\lambda=650 \mathrm{~nm}$, using Shimadzu UVVisible recording spectrophotometer type UV160A. Iron concentration was determined by EDTA titration. Density and solid content of the solution were determined by conventional methods. Energy dispersive X-ray (EDX), atomic absorption and spectrophotometric analysis of the final ppt. products were carried out.

\section{Experimental procedure}

Extraction of uranium takes place using fixed bed and batch method and there are two processes considered, namely, extraction process and elution process.

\section{Uptake process}

Batch technique (dynamic)

Uptake of uranium from sulfate leach solution takes place using 1.0 gram of resin (Amberlite IRA400 $\left(\mathrm{Cl}^{-}\right)$and $20 \mathrm{ml}$ of the aqueous solution which contain $800 \mathrm{ppm}$ of uranium and this done at room temperature $25 \pm 1{ }^{\circ} \mathrm{C}$. In this work the resin and the solution left to equilibrate for $20 \mathrm{~min}$. with stirring.

To determine the uranium concentration, known aliquots were taken from the aqueous solution before and after extraction for spectrophotometrical assay.

The uptake percentage (\% Uptake) can be calculated from the relation:

$$
\% \text { Uptake }=\left(\mathrm{C}_{\text {initial }}-\mathrm{C}_{\text {remain }}\right) \mathrm{X} 100 / \mathrm{C}_{\text {initial }}
$$

Where $\mathrm{C}$ initial and $\mathrm{C}$ remain are the initial concentration of uranium in aqueous solution and the concentration of uranium remains in the solution after contacting with resin respectively.

\section{Fixed bed technique}

Trials were carried out in a glass column which operated with the industrial effluent, at a flow rate of 1,2 and $3 \mathrm{~mL} / \mathrm{min}$, at $\mathrm{pH} 4.0$ and room temperature. Ten milliliter of resin Rohm and Haas IRA 400 (Cl-), previously treated with $\mathrm{NaCl}$ to regenerate the resin, then packed into a glass column. The operation was performed by downstream flow. The adsorbed uranium was eluted with sodium chloride solution $0.5,1.0,2.0$ and $3.0 \mathrm{~mol} / \mathrm{L}$. The original industrial effluent was diluted and used as eluent also. Dilution was necessary to avoid uranium precipitation into the resin.

\section{Elution process}

Elution of the extracted uranium from resin (Amberlite IRA400) was achieved by; sodium chloride $(1.0 \mathrm{M} \mathrm{NaCl})$. The elution process was carried out by shaking the resin and the sodium chloride solution till equilibrium. After filtration, the concentration of uranium before and after elution was determined. The uranium elution percentage (\% Recovery) was calculated as follows;

$$
\% \text { U Recovery }=\left(\mathrm{C}_{\text {load }}-\mathrm{C}_{\text {remain }}\right) \mathrm{X} 100 / \mathrm{C}_{\text {load }}
$$

Where $\mathrm{C}_{\text {load }}$ and $\mathrm{C}_{\text {remain }}$ are the concentration of uranium loaded onto the resin and the concentration of uranium in the aqueous solution after elution respectively. 
Table (1): Physical and chemical characters of the working solution

\begin{tabular}{lllllll}
\hline Color & $\begin{array}{l}\text { Density, } \\
\mathrm{g} / \mathrm{cm}^{3}\end{array}$ & $\begin{array}{l}\text { Solid content, } \\
\mathrm{g} / \mathrm{l}\end{array}$ & $\mathrm{U}, \mathrm{g} / \mathrm{l}$ & $\mathrm{Fe}, \mathrm{g} / \mathrm{l}$ & $\mathrm{pH}$ & $\begin{array}{l}\mathrm{H}_{2} \mathrm{SO}_{4} \\
\text { Conc., } \mathrm{mol} / \mathrm{L}\end{array}$ \\
\hline yellow & 1.04 & 11.44 & 0.8 & 1.676 & 0.45 & 0.5 \\
\hline
\end{tabular}

Scanning electron microscope (EDX)

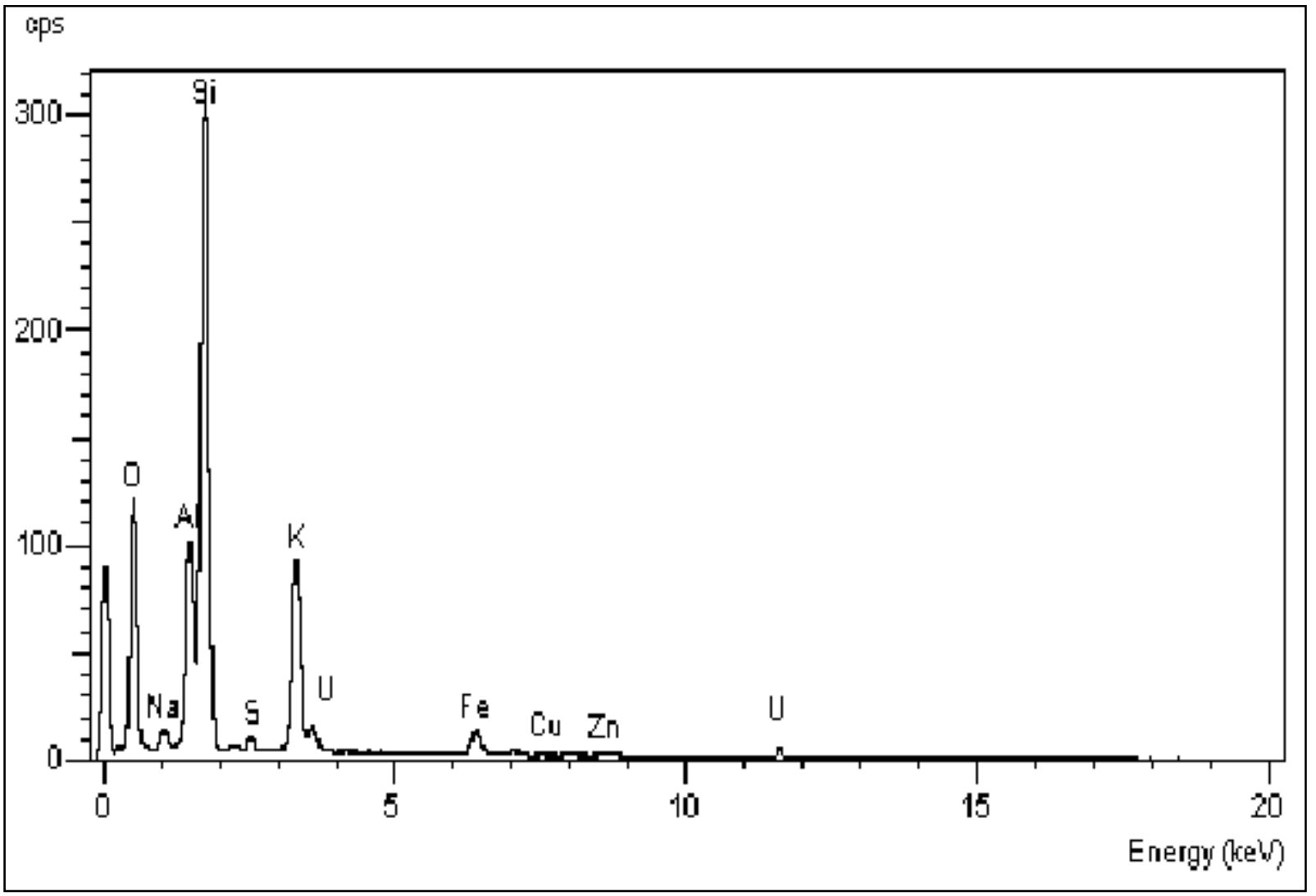

Figure (1): EDX analysis of the working sample

Results and Discussion

In sulphate medium uranium forms the following stable complexes with sulphate ions: $\mathrm{UO}_{2} \mathrm{SO}_{4}$, $\mathrm{UO}_{2}\left(\mathrm{SO}_{4}\right)_{2}{ }^{2-}$ and $\mathrm{UO} 2(\mathrm{SO} 4) 34-$. The values of their cumulative stability constants (ß) are 64.6, 316 and 5012, respectively [22]. The mole fraction (Ø) of individual species can be calculated from the known equation [23].

$$
\Phi_{i}=\frac{\beta_{i}[L]^{i}}{1+\sum_{i=1}^{N} \beta_{i}[L]^{i}}
$$

Where $\mathrm{L}$ denotes ligand (in this case $\mathrm{SO}_{4}{ }^{2-}$ ion). Mole fractions of $\mathrm{UO}_{2}{ }^{2+}-\mathrm{SO}_{4}{ }^{2-}$ complexes as a function of the ligand concentration are shown in Fig. (2). As can be seen, at concentration of $\mathrm{SO}_{4}{ }^{2-}$ exceeding $0.1 \mathrm{~mol} / \mathrm{L}$ uranium exists predominantly in the anionic form of $\mathrm{UO}_{2}\left(\mathrm{SO}_{4}\right)_{3}{ }^{4-}$. Its sorption by strongly basic ion exchange resins of Amberlite IRA400 type can be schematically written as [24].

$\mathrm{UO}_{2}\left(\mathrm{SO}_{4}\right)_{3}{ }^{4-}+2 \mathrm{R}_{2} \mathrm{SO}_{4} \rightarrow \mathrm{R}_{4} \mathrm{UO}_{2}\left(\mathrm{SO}_{4}\right)_{3}+2 \mathrm{SO}_{4}{ }^{2-}$ 


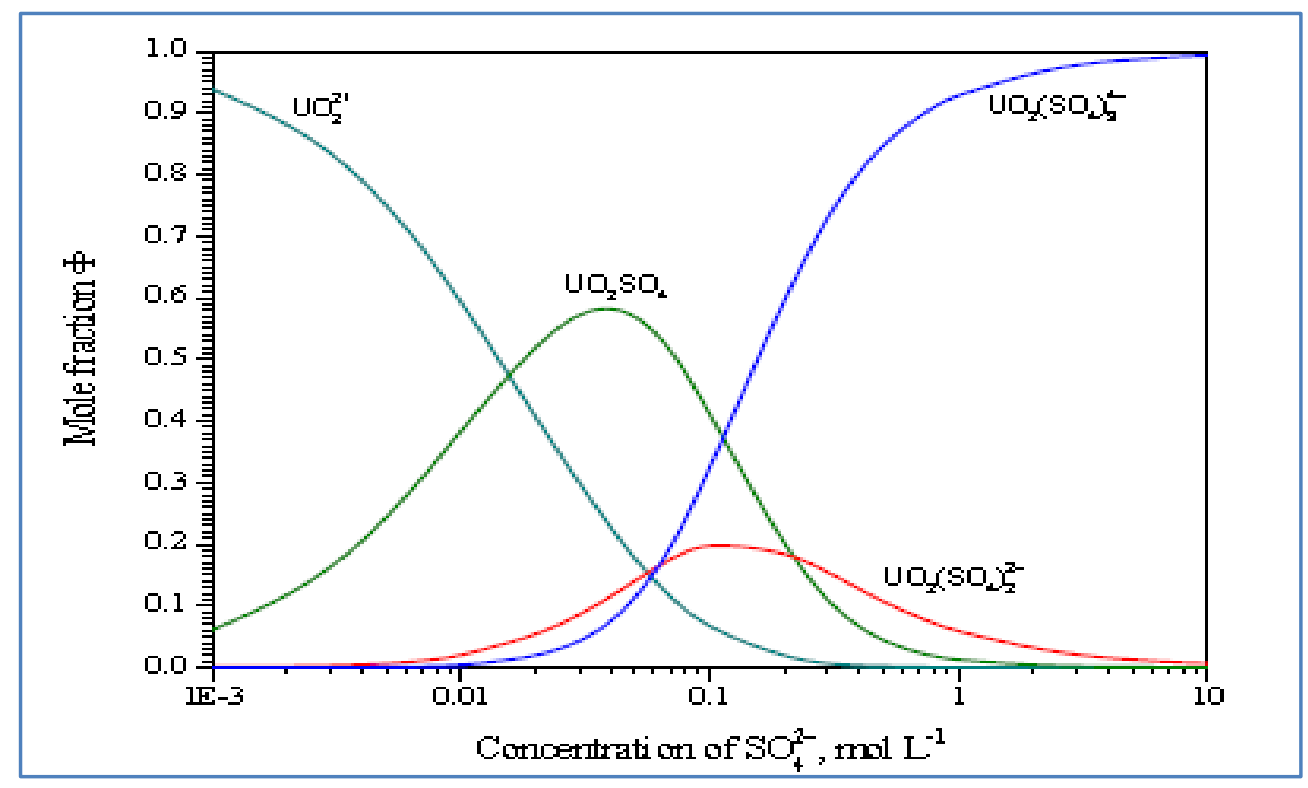

Fig. (2): Mole fractions of uranium sulphate complexes as a function of $\mathrm{SO}_{4}{ }^{2-}$ concentration

Where barred symbols refer to the ion exchanger phase and $\mathrm{R}$ denotes a structural unit of an ion exchanger.

The selectivity coefficient can be calculated using the mathematical derivation for the above equation using the mass distribution coefficient. After rearrangement and transformation into logarithmic form, the graphical relation between the concentration of sulphate and bisulphate and the distribution coefficient can determine the predominant species in the medium depend on the value of the slope. If the slope equals -2 , the predominant species will be $\mathrm{SO}_{4}{ }^{2-}$ form and if the value of the slope equals -4 , the predominant species will be $\mathrm{HSO}_{4}{ }^{-}$.

By applying the relation between sulphuric acid and the calculated mass distribution coefficient on the Amberlite IRA400 for recovery of uranium from the prepared sample, the slope obtained from the graph Fig. (3) equals -2.9 which indicated that a mixed species from sulphate and bisulphate in the worked sample.

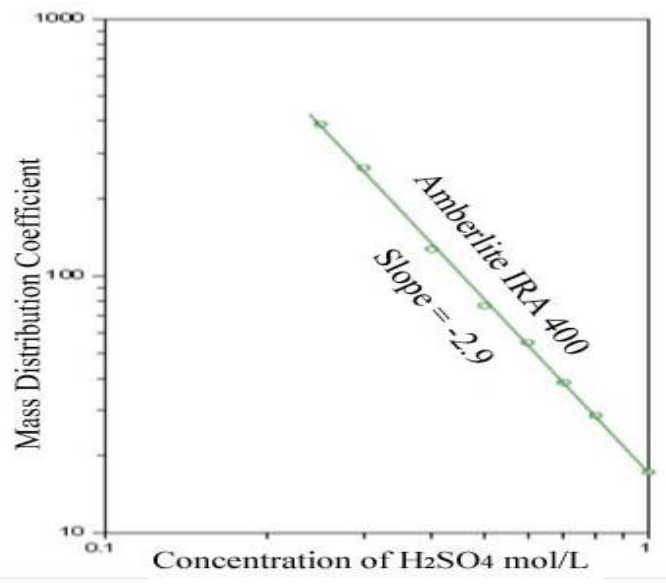

Fig. (3): Mass distribution coefficient of uranium as a function of $\mathrm{H}_{2} \mathrm{SO}_{4}$ concentration for anion exchange resins of Amberlite IRA 400

\section{Batch investigations}

The different factors affecting the uptake of uranium from working solutions were determined. This was followed by investigating the different parameter affecting the stripping of uranium from loaded resin.

\section{Factors affecting uranium uptake}

Effect hydrogen ion concentration

The $\mathrm{pH}$ of the working waste solution was adjusted using diluted solution of $0.1 \mathrm{M} \mathrm{NaOH}$ and $0.1 \mathrm{M}$ $\mathrm{HNO}_{3}$ the \%Uptake of uranium from the solution was carried out and the results are given in Fig. (4). From this figure, it is clear that the $\%$ uptake 
of uranium gradually increased by increasing the $\mathrm{pH}$ of the solution from $\mathrm{pH}=0.5$ to reach maximum uptake of $90 \%$ between $\mathrm{pH}=1.75$ up to $\mathrm{pH}=3.0$.

\section{Effect of shaking time}

Measurements to define the equilibrium time was done at $\mathrm{pH} \sim 2.0$ by shaking 1.0 gram of resin with $20 \mathrm{ml}$ of metal ion solution from $2.0 \mathrm{~min}$. to 120 min., at room temperature $28 \pm 1^{\circ} \mathrm{C}$. The results are given in Fig. (5). Show that the extraction percentage increases with increasing the shaking time to $20 \mathrm{~min}$. then the uptake process becomes nearly stable, which means that the equilibrium time takes place after $20 \mathrm{~min}$.

\section{Effect of temperature}

The effect of temperature on the adsorption of metal ions was carried out at different temperatures $28,40,50,60$ and $70{ }^{\circ} \mathrm{C}$ by placing 1.0 gram of resin in a series of flasks containing $20 \mathrm{ml}$ of metal ion solutions at $\mathrm{pH} \sim 2$ and shaking time of 20 min. From the data in Fig. (6) it was found that the uptake slightly increased to reach a maximum value between $40-50^{\circ} \mathrm{C}$. this was followed by a continuous decrease at a higher temperature. Therefore, the optimum temperature considered is $\simeq 40^{\circ} \mathrm{C}$.

\section{Effect of resin to solution $(R / S)$ ratio}

The effect of the ratio of resin to solution on the uptake of metal ions was measured at different ratios $1: 5,1: 10,1: 20,1: 30,1: 40,1: 60$, and $1: 80$ by placing $1.0 \mathrm{~g}$ of resin in a series of flasks containing different volumes $(\mathrm{ml})$ of metal ion solutions at $\mathrm{pH} \sim 2$, shaking time of $20 \mathrm{~min}$. and at $40^{\circ} \mathrm{C}$. The data, shown in Fig. (7), illustrates that as the volume of the leach solution increases, the uptake percentage increased up to the ratio $1: 5 \mathrm{R} / \mathrm{S}$ ratio which led to uptake percentage of $97.3 \%$

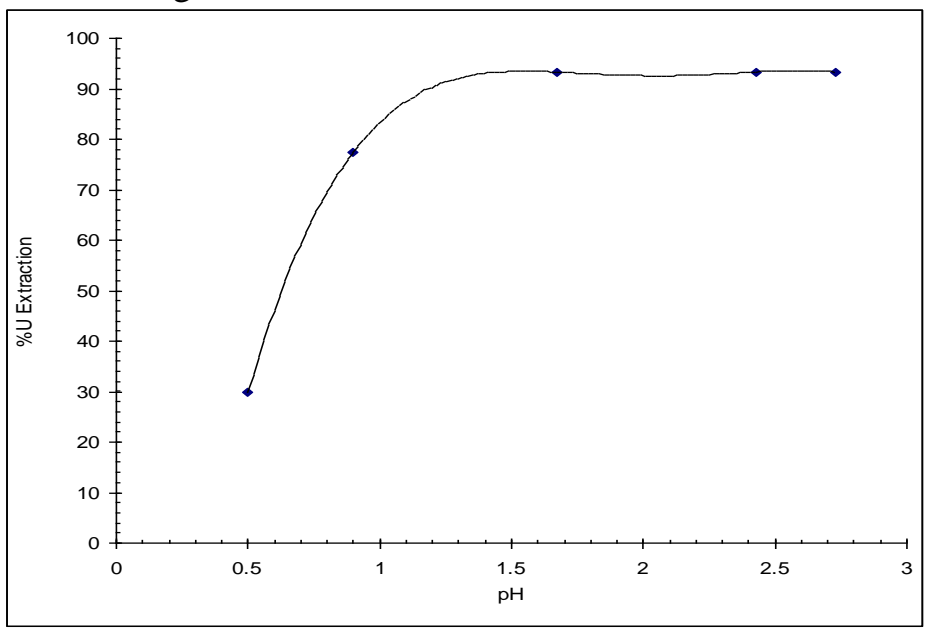

Fig. (4): Effect of $\mathrm{pH}$ on extraction of uranium, $\mathrm{R} / \mathrm{S}$ ratio $=1: 20$, shaking time $=20 \mathrm{~min}$, and temperature $=28 \pm 1^{\circ} \mathrm{C}$

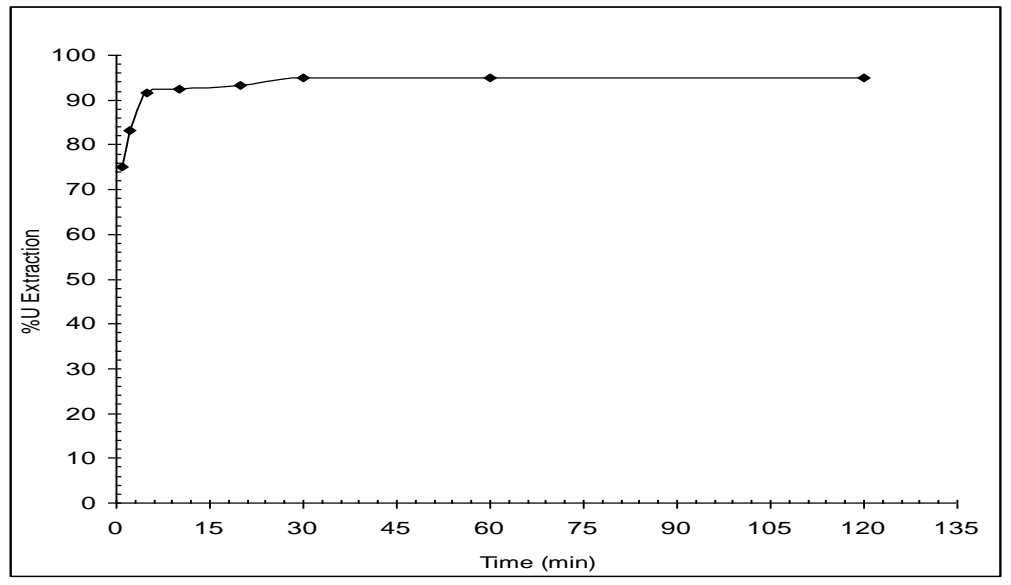

Fig. (5): Effect of shaking time on uptake of uranium, $\mathrm{pH}=2, \mathrm{R} / \mathrm{S}$ ratio $=1: 20$, and temperature $=28 \pm 1^{\circ} \mathrm{C}$ 


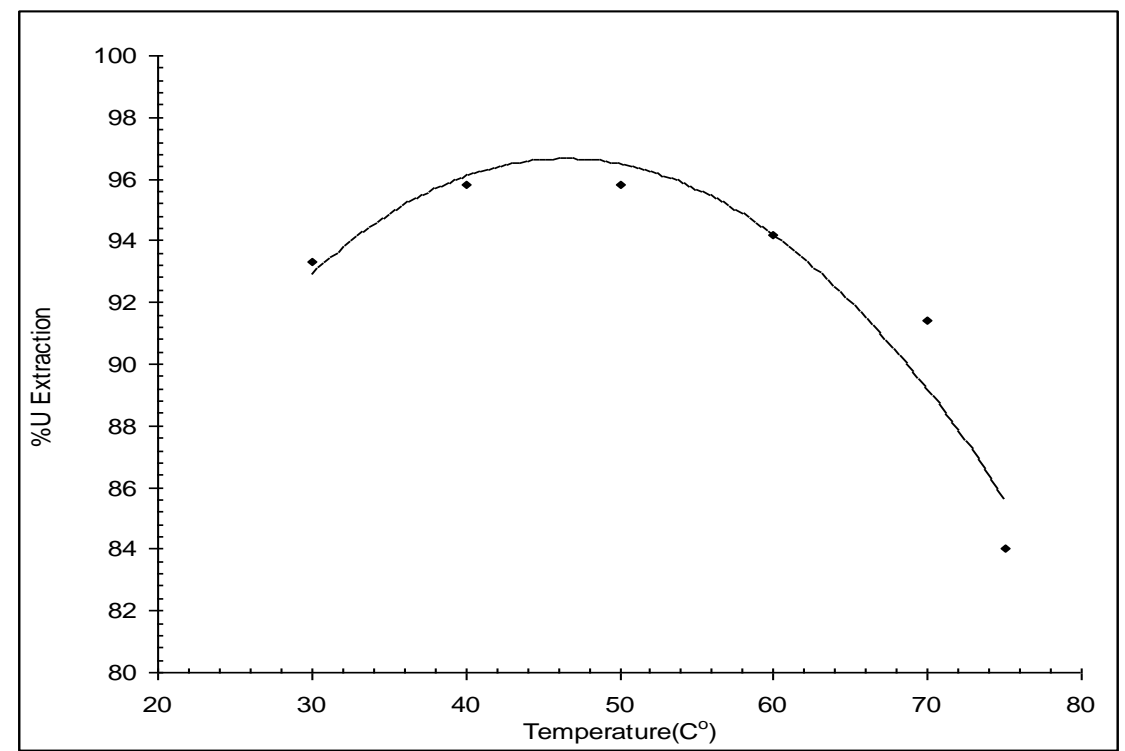

Fig. (6): Effect of temperature on uptake of uranium, $\mathrm{R} / \mathrm{S}$ ratio $=1: 20, \mathrm{pH}=2$, and shaking time $=20 \mathrm{~min}$

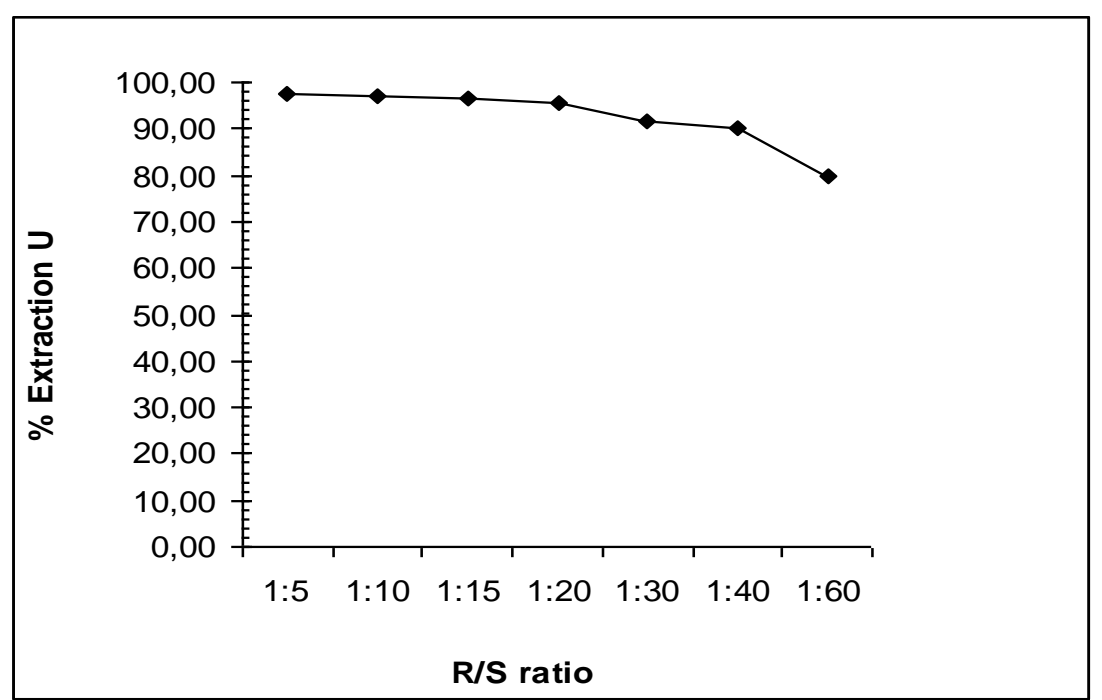

Fig. (7): Effect of Resin to Solution ratio on uptake of uranium, $\mathrm{pH}=2$, shaking time $=20 \mathrm{~min}$, and temperature $=40^{\circ} \mathrm{C}$

Factors affecting stripping of uranium from the resin

Adding different stripping agent

Recovery of uranium from the loaded resin was tested by using different eluent with different concentrations of $\mathrm{NaCl}, \mathrm{Na}_{2} \mathrm{SO}_{4}$, and $\mathrm{Na}_{2} \mathrm{CO}_{3}$. By placing 1.0 gram of the loaded resin in a round flask containing $20 \mathrm{ml}$ of the prepared eluent solutions, then shaking for $20 \mathrm{~min}$. at room temperature. It was found that a maximum recovery $65.7 \%$, obtained using $1.0 \mathrm{M} \mathrm{NaCl}$ (Fig. 8).

\section{Effect of shaking time}

Effect of shaking time on uranium recovery from the loaded resin has been investigated using 1.0 gram of loaded resin. The shaking time was varied from 1 to 120 minutes using $20 \mathrm{ml} 1 \mathrm{M} \mathrm{NaCl}$ and temperature $28+1{ }^{\circ} \mathrm{C}$. The obtained results presented in Fig. (9) indicate that the recovery of uranium increases with shaking time, then the extraction process become nearly stable after 40 min., which means that the equilibrium time takes place after $40 \mathrm{~min}$. On the other side, $20 \mathrm{~min}$. was chosen which is the best from the economic point of view. 


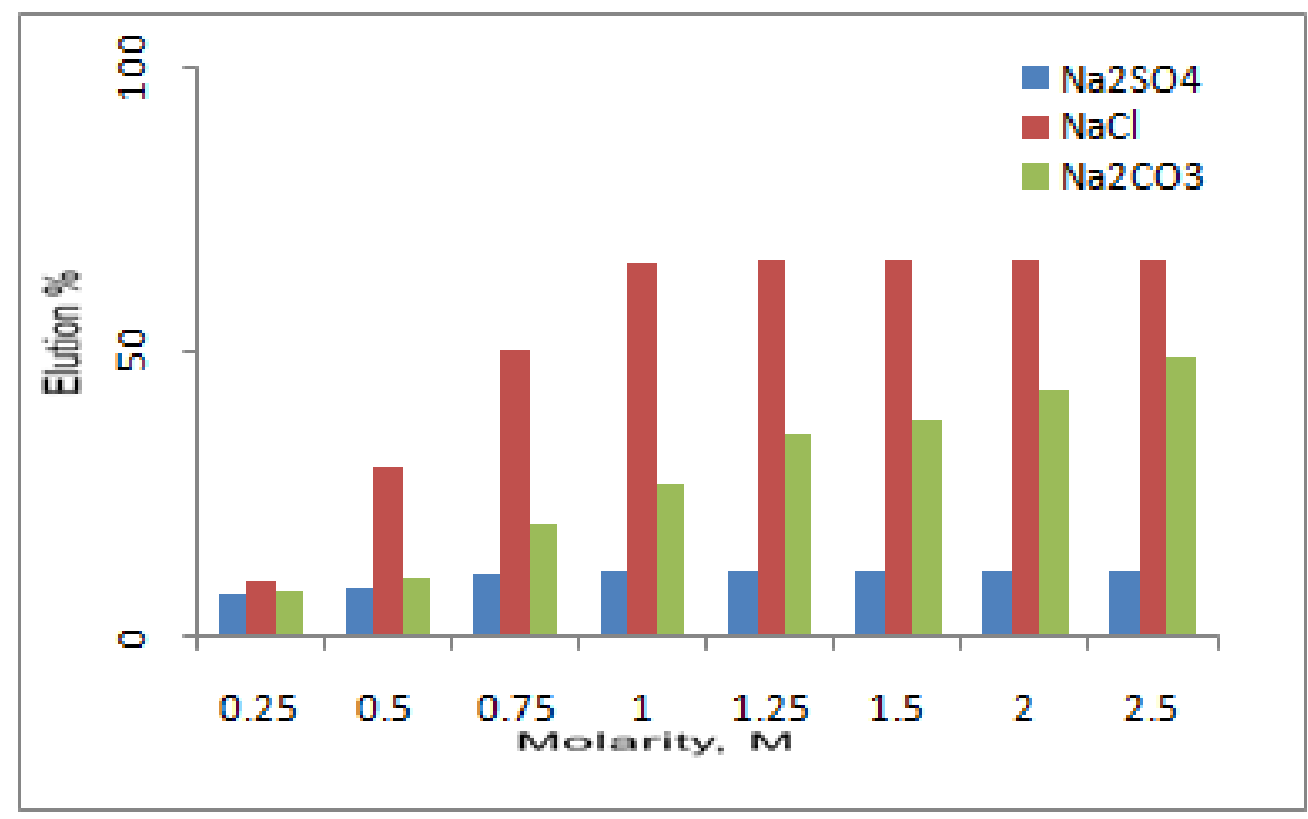

Fig. (8): Effect of using different concentrations of different eluent, $R / \mathrm{S}$ ratio $=1: 20$, shaking time $=20 \mathrm{~min}$, and temperature $=28 \pm 1^{\circ} \mathrm{C}$

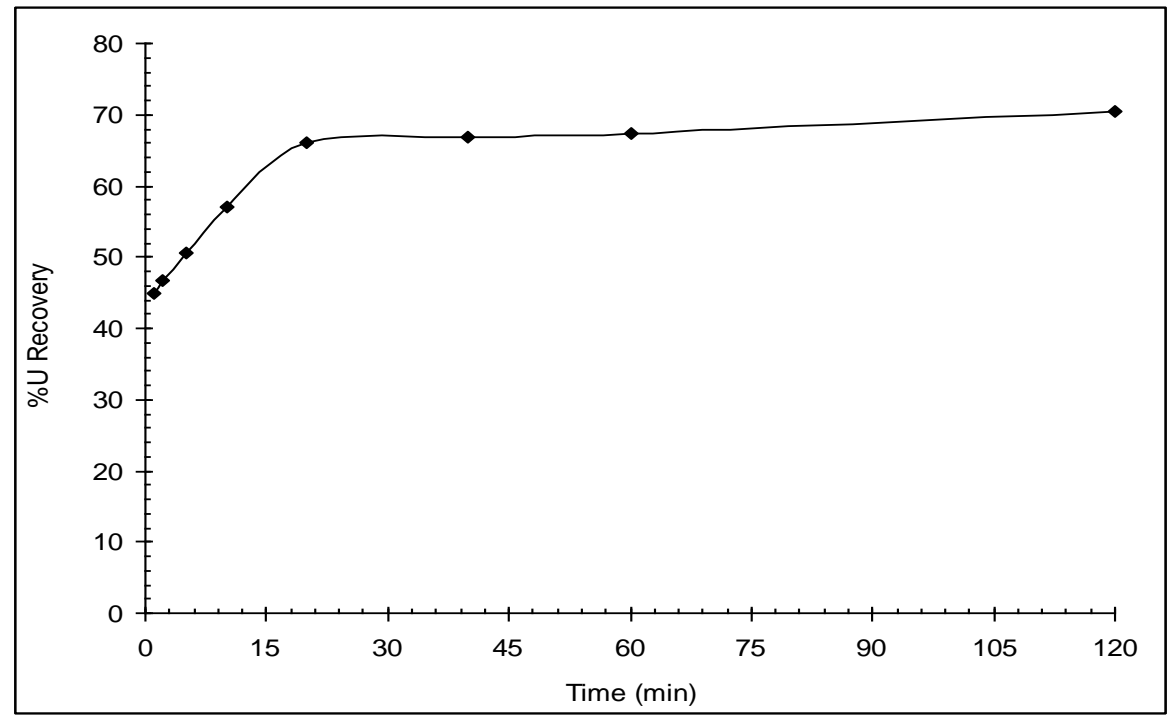

Fig. (9): Effect of using shaking time on the recovery of uranium, $\mathrm{R} / \mathrm{S}$ ratio $=1: 20$, concentration of $\mathrm{NaCl}=1.0 \mathrm{M}$, and temperature $=28 \pm 1^{\circ} \mathrm{C}$

Effect of temperature on the recovery of uranium By taking $20 \mathrm{ml}$ of $1.0 \mathrm{M} \mathrm{NaCl}$ solution with $1.0 \mathrm{~g}$ of the loaded resin, shaking time $20 \mathrm{~min}$. and temperature was varied from 30 to $80^{\circ} \mathrm{C}$. The obtained results shown in Fig. (10) indicate that the recovery of uranium decreased from $66.4 \%$ to $54.3 \%$ at $30^{\circ} \mathrm{C}$ and $40^{\circ} \mathrm{C}$, respectively. Thus, the recovery of uranium decreases till reaching to $40^{\circ} \mathrm{C}$, then it becomes nearly stable which indicated that at a higher temperature, the extraction of uranium again instead of chloride ions.

\section{Effect of resin to solution $(R / S)$ ratio}

Recovery of uranium takes place by taking 1.0 gram of the loaded resin with different volumes of $1 \mathrm{M} \mathrm{NaCl}$, shaking time $20 \mathrm{~min}$. and temperature at $30{ }^{\circ} \mathrm{C}$ with different $\mathrm{R} / \mathrm{S}$ ratios from $1: 5$ to $1: 160$. The obtained results are presented graphically in Fig. (11). It was found that the recovery of uranium from the loaded resin decreases gradually with increasing the volume of the solution, which indicates that the resin sites have high affinity toward the chloride ions rather than uranium 
complexes. The maximum recovery was $98 \%$ at 1:5 ratios which gives the maximum recovery with the minimum volume (volume reduction).

Fixed bed investigation (Amberlite IRA400 $\mathrm{Cl}^{-}$ resin)

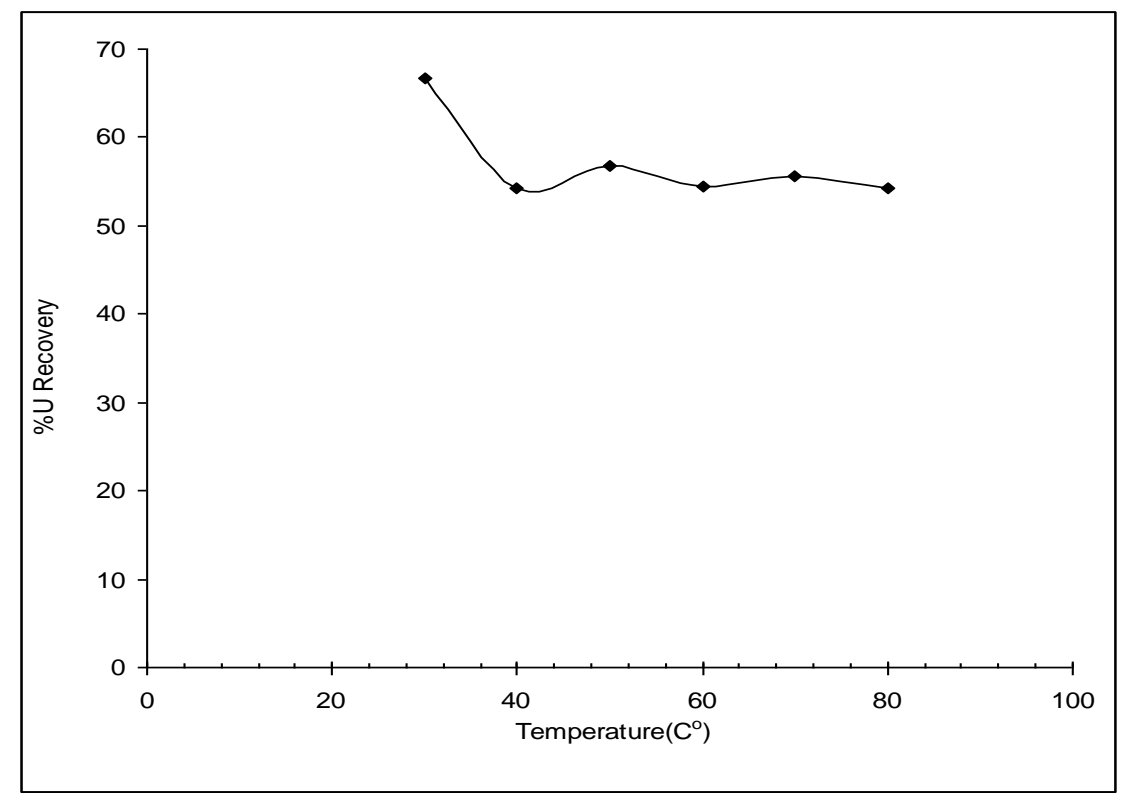

Fig. (10): Effect of temperature on the recovery of uranium, $R / S$ ratio $=1: 20$, shaking time $=20$ min, and concentration of $\mathrm{NaCl}=1.0 \mathrm{M}$

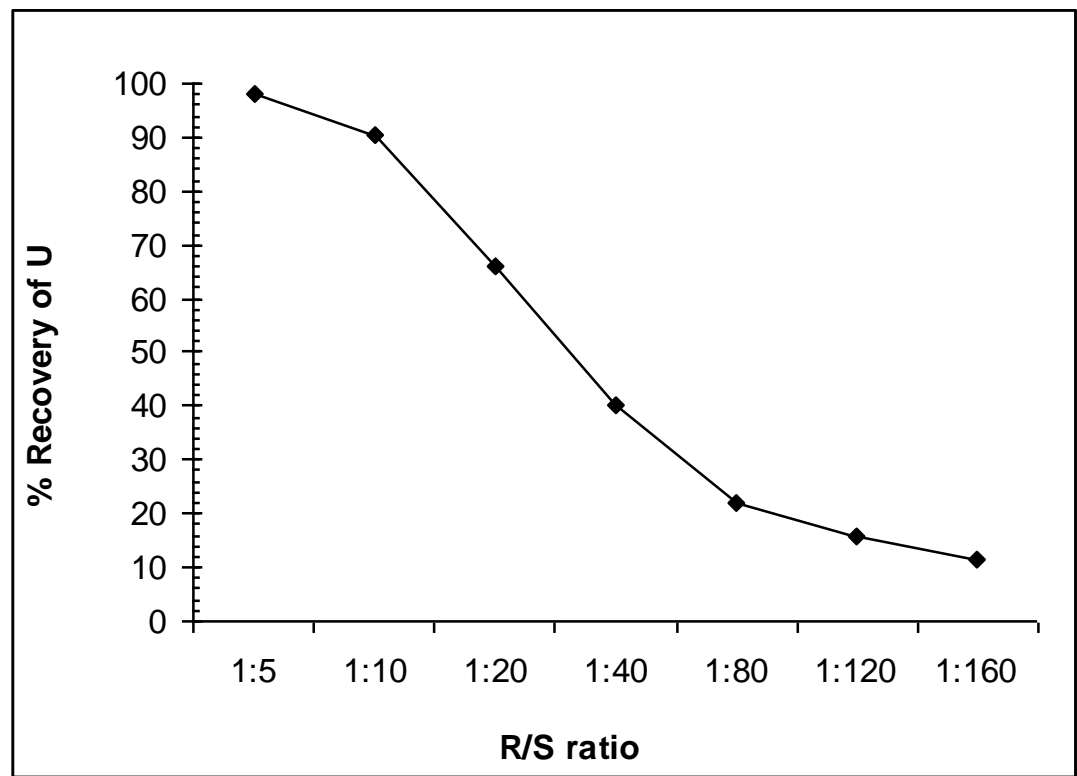

Fig. (11): Effect of $(\mathrm{R} / \mathrm{S})$ ratio on the recovery of uranium, shaking time $=20 \mathrm{~min}$, temperature $=30{ }^{\circ} \mathrm{C}$ and concentration of $\mathrm{NaCl}=1.0 \mathrm{M}$
A column of glass of $1 \mathrm{~cm}$ diameter and of $25 \mathrm{~cm}$ length was prepared and packed by Amberlite IRA 400 in the chloride form. Different parameters were applied and studied for such a column. 


\section{Effect of flow rate}

The breakthrough curves of the studied resin towards adsorption of uranium at flow rates of 1.0, 2.0 and $3.0 \mathrm{ml} / \mathrm{min}$ and a fixed bed height of $10 \mathrm{~cm}$ are presented in Fig. (12). It is noticed that breakthrough and exhaustion of the resin occur faster at higher flow rates. Also, as the flow rate increases, the uranium concentration in the effluent increased rapidly resulting in much sharper breakthrough curves. This behavior may be attributed to the insufficient residence time for the uptake of the uranium by the resin in the column. This negatively affects the interaction process as well as the diffusion of uranium through the pores of the resin [25]. At the same bed height and a flow rate of $1 \mathrm{ml} / \mathrm{min}$, the longer breakthrough time which refer to its higher affinity and strong binding with the resin's active sites.

\section{Effect of fixed bed height}

The bed height was studied at $5,10,15$ and $18 \mathrm{~cm}$ while the flow rate was held constant at 1.0 $\mathrm{mL} / \mathrm{min}$. The data obtained are shown in Fig. (13). The influence of bed height on the removal efficiency was well tested in terms of breakthrough time $\left(t_{b}\right)$ and saturation time $\left(t_{s}\right)$. The removal efficiency of the resin was found to be directly proportional with bed height. Bed depth service time model (BDST) is a simple model, which states that bed height $(\mathrm{Z})$ and saturation time $\left(\mathrm{t}_{\mathrm{s}}\right)$ of the column give a linear relationship, as given in the following equation [26]:

$$
\mathrm{t}_{\mathrm{s}=} \frac{N_{o} Z}{C_{o} v}-\frac{1}{K_{a} C_{o}} \ln \left(\frac{C_{o}}{C_{t}}-1\right)
$$

Where $C_{t}$ is the concentration of the uranium ion at the saturation time just prior equalizing the initial concentration $C_{o}$ (i.e. $C_{o} / C_{t}=100 / 99$ ), $N_{o}$ is the total adsorption capacity (mmol of solute/ $\mathrm{L}$ of sorbent bed), $v$ the linear velocity $(\mathrm{cm} / \mathrm{min})$ and $\mathrm{K}_{\mathrm{a}}$ is the rate constant of transfer of the uranium to the resin surface (L/mmol. min). The values of $\mathrm{N}_{\mathrm{o}}$ and $\mathrm{K}_{\mathrm{a}}$ were calculated from the slope and intercept of the BDST plots, Fig.13. If $\mathrm{K}_{\mathrm{a}}$ is large, even a short resin's bed depth will avoid the breakthrough limit. In case of small values of $\mathrm{K}_{a}$, a progressively longer bed would be required to extend the breakthrough point. The value of $\mathrm{K}_{a}$ for uranium is 144 (L/mmol. min). This refers to the higher efficiency of the resin to recover uranium.

\section{Effect of $\mathrm{pH}$ of the solution}

The adsorption measurement under controlled $\mathrm{pH}$ was conducted using $1 \mathrm{M} \mathrm{NH}_{4} \mathrm{OH} \& 1 \%$ sulphuric acid. The $\mathrm{pH}$ of the media which contains the uranium studied ranged from 1 to 6 at flow rates of $1 \mathrm{~mL} / \mathrm{min}$ and a fixed bed height of $18 \mathrm{~cm}$ as presented in Fig. (14) It is noticed that the adsorption percentage increased with the increase of the $\mathrm{pH}$ markedly till reaching $\mathrm{pH}=4$ which gives about $94 \%$ extraction of uranium, and then the adsorption decreased after this value.

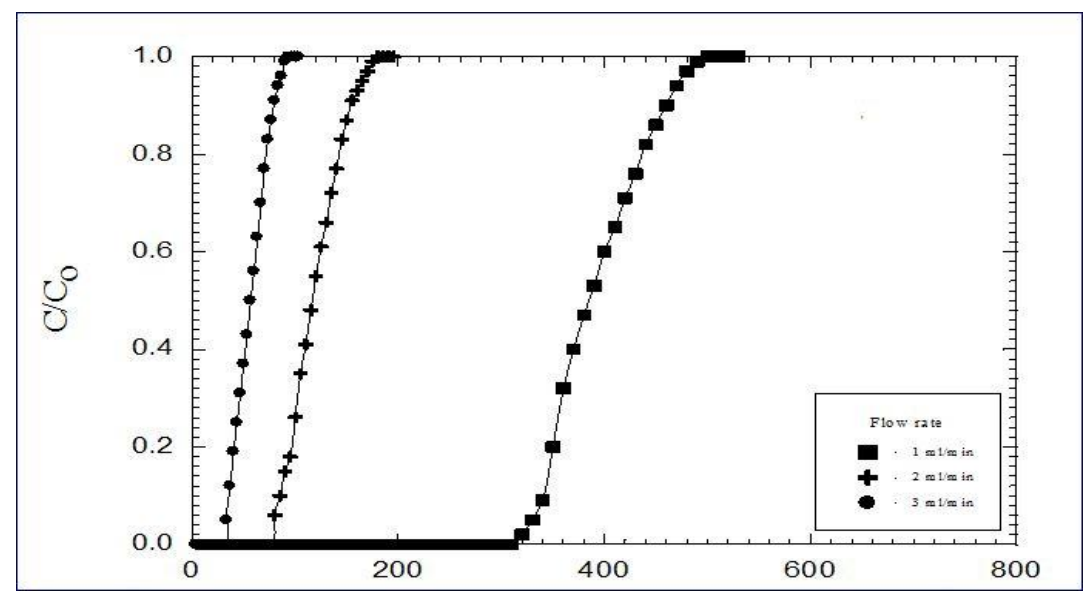

Fig. (12): Effect of flow rate on purification of uranium, bed height $=10 \mathrm{~cm}, \mathrm{H}_{2} \mathrm{SO}_{4}$ conc. $=0.5 \mathrm{M}$, and $\mathrm{pH}=0.45$ 


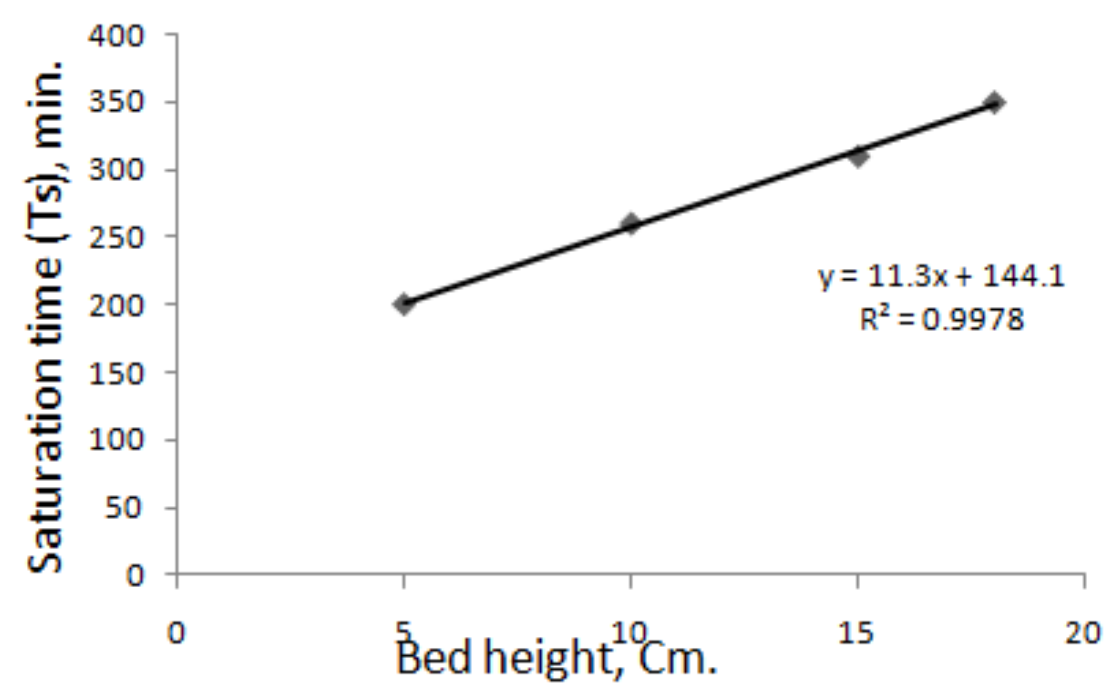

Fig. (13): Effect of bed height on purification of uranium, flow rate $=1.0 \mathrm{~mL} / \mathrm{min}, \mathrm{H}_{2} \mathrm{SO}_{4}$ conc. $=0.5 \mathrm{M}$, and $\mathrm{pH}=0.45$

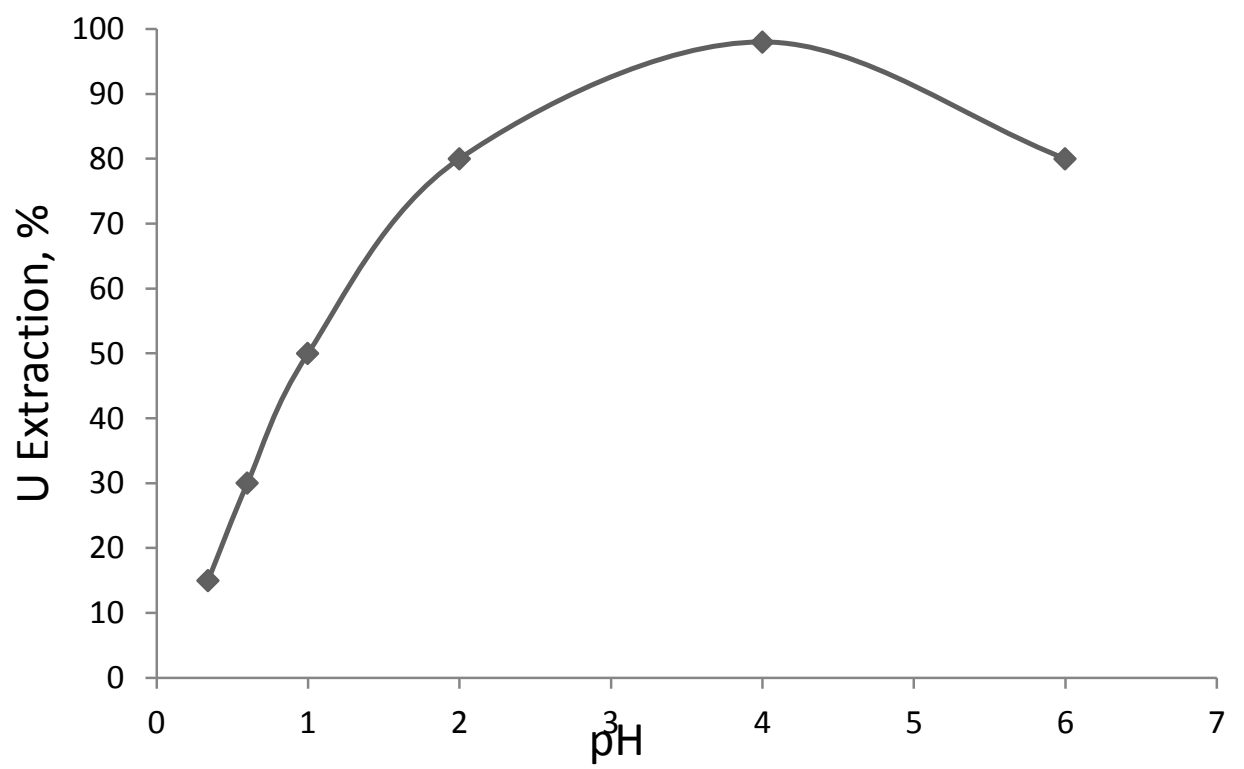

Fig. (14): Effect of $\mathrm{pH}$ on purification of uranium, flow rate $=1.0 \mathrm{~mL} / \mathrm{min}$, bed height $=18 \mathrm{~cm}$, and $\mathrm{H}_{2} \mathrm{SO}_{4}$ conc. $=0.5 \mathrm{M}$

\section{Elution and regeneration}

\section{Effect of $\mathrm{HCl}$ concentration}

To reduce the process cost and dependency of the process on continuous supply of the sorbent, Amberlite resin was regenerated using different concentration of $100 \mathrm{ml}$ of $\mathrm{HCl}$ ranged from 0.1 to $8 \mathrm{M}$ and at flow rates of $1 \mathrm{~mL} / \mathrm{min}$ as shown in Fig. (15). Sorption/desorption were carried out on charged column with the resin. The column was loaded with uranium. Elution efficiency was calculated and found to be $98 \%$ at $1.0 \mathrm{M}$ of $\mathrm{HCl}$.

\section{Effect of volume of $\mathrm{HCl}$ added}

The elution measurement using $1.0 \mathrm{M} \mathrm{HCl}$ takes place using different volume of the acid to reach a complete removal of uranium from the resin. The variation of the volume of $\mathrm{HCl}$ takes place from 10 to $120 \mathrm{ml}$ of $1.0 \mathrm{M} \mathrm{HCl}$ as shown in Fig. (16) It is noticed that the elution percentage increased with the increase of the volume of $1 \mathrm{M} \mathrm{HCl}$ markedly to reach $100 \mathrm{ml}$ then the elution become constant after this value. The elution efficiencies were found to be $99 \%$ at $100 \mathrm{ml}$ of $1.0 \mathrm{M} \mathrm{HCl}$. 


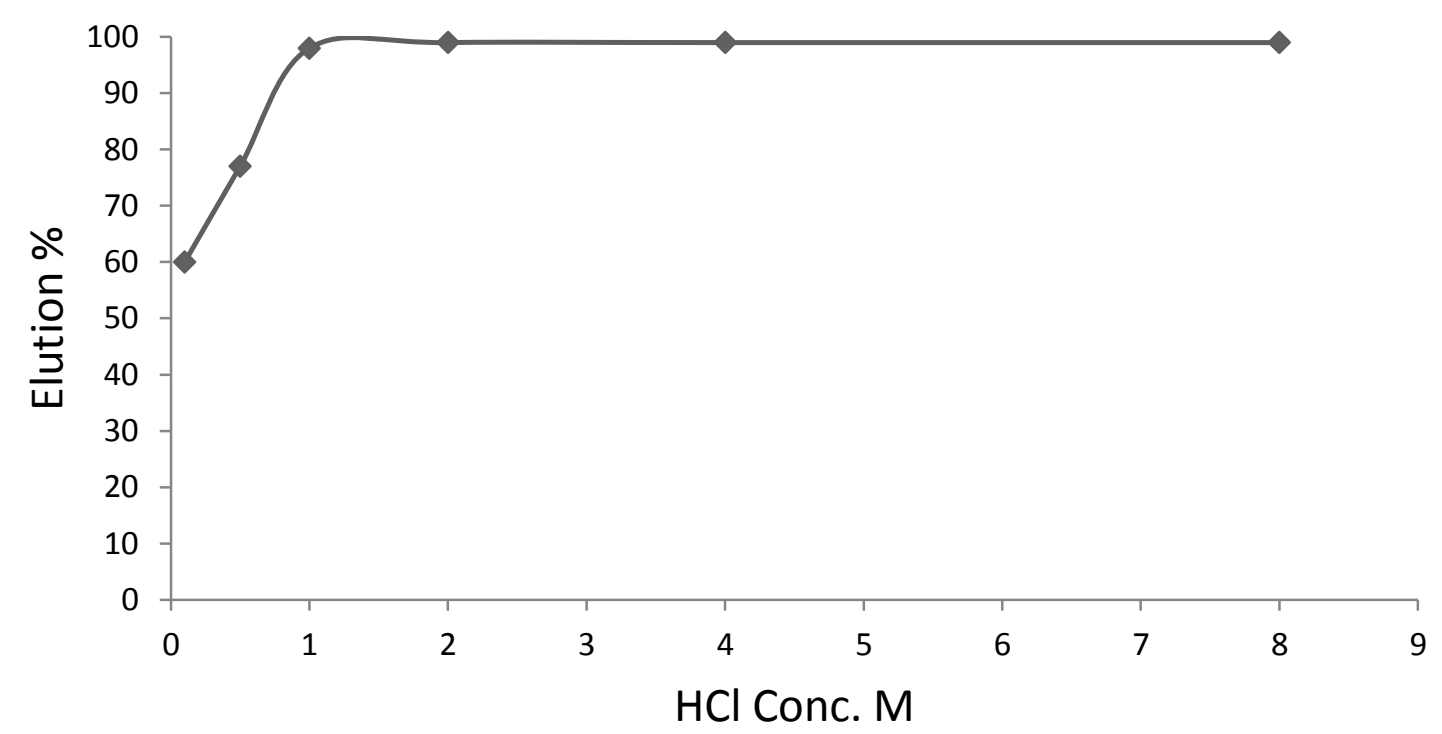

Fig. (15): Effect of $\mathrm{HCl}$ conc. on recovery of uranium, flow rate $=1.0 \mathrm{~mL} / \mathrm{min}$, bed height $=18 \mathrm{~cm}$ and volume of $\mathrm{HCl}=100$ ml

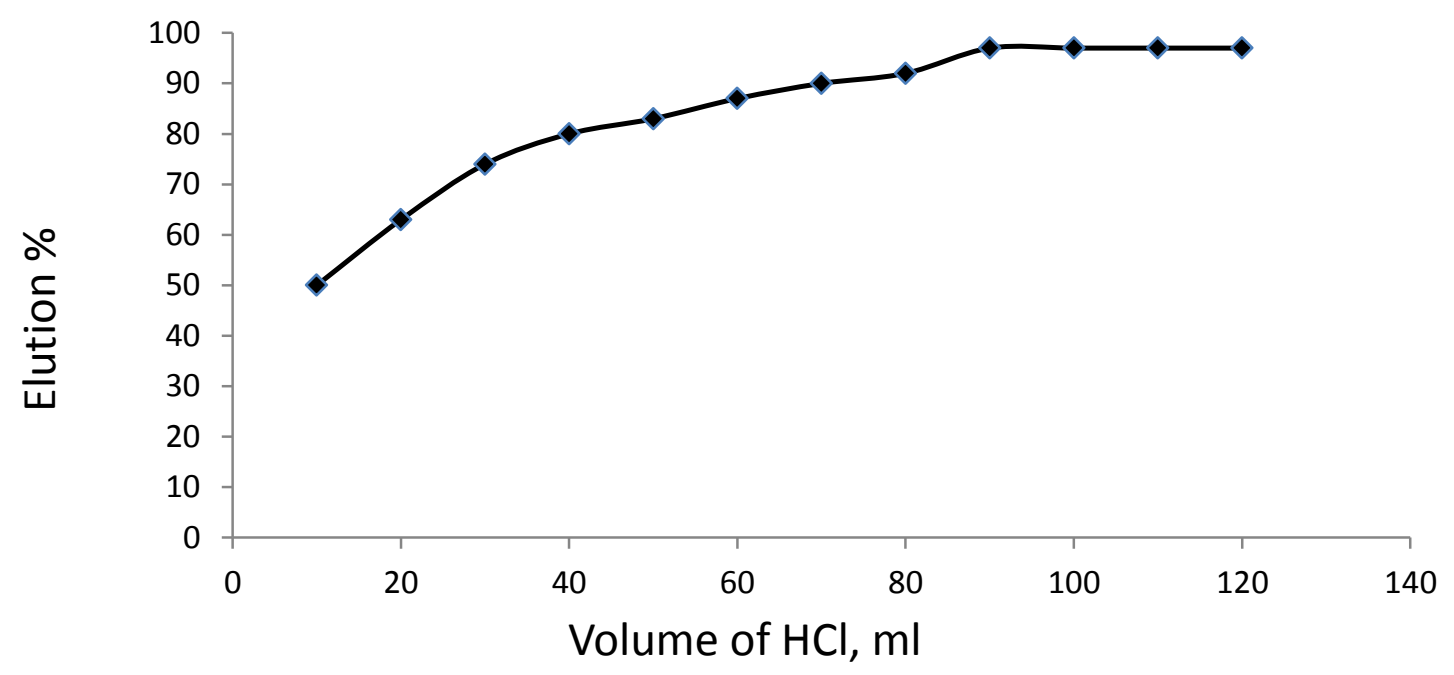

Fig. (16): Effect of volume of $\mathrm{HCl}$ on recovery of uranium, flow rate $=1.0 \mathrm{~mL} / \mathrm{min}$, bed height $=18 \mathrm{~cm}$, and $\mathrm{HCl}$ conc. $=1.0$

\section{Specification of produced yellow cake}

Analysis of the yellow cake by the Amberlite IRA400 Cl- resin is given in Table (2) together with the international specifications of the yellow cake. From this table, it is clear that the main

neutron poisoning elements such as boron and cadmium are not present. On the other hand, the specifications of the yellow cake sample produced meet the international standards [28].
To test the beneficiation of dynamic ion exchange through agitation and classical fixed bed ion exchange, determination the breakthrough curve was pre-defined as the number of bed volumes of 40 and the required time was 200 minutes with flow rate $1.0 \mathrm{ml} / \mathrm{min}$. The obtained results of the application of dynamic ion exchange in a separate batch by the same ratios are shown in Table (3). This refers to a considerable shortening in operation time from 200 minutes to only 15 minutes in dynamic ion exchange. In addition to 
that, the quantity of the feed solution was treated

without the presence of very low flow rates.

Table (2): Specifications of produced yellow cake

\begin{tabular}{|c|c|c|c|c|c|}
\hline Specification & $\begin{array}{l}\text { International } \\
\text { Yellow cake } \\
\text { limit }\end{array}$ & $\begin{array}{l}\text { Produced } \\
\text { Yellow cake }\end{array}$ & Specification & $\begin{array}{l}\text { International } \\
\text { Yellow cake } \\
\text { limit }\end{array}$ & $\begin{array}{l}\text { Produced } \\
\text { Yellow cake }\end{array}$ \\
\hline Uranium (U) & $65 \%$ min. & $74.2 \%$ & Mercury (Hg) & Nil & Nil \\
\hline Arsenic (As) & $0.1 \%$ & Nil & $\begin{array}{l}\text { Molybdenum } \\
\text { (Mo) }\end{array}$ & $0.3 \%$ & $0.0004 \%$ \\
\hline Barium (Ba) & Nil & Nil & Potassium (K) & $3 \%$ & $<0.002$ \\
\hline Boron (B) & Nil & Nil & Silica $\left(\mathrm{SiO}_{2}\right)$ & $2.5 \%$ & Nil \\
\hline Cadmium (Cd) & Nil & Nil & Silver (Ag) & Nil & $0.0003 \%$ \\
\hline Calcium (Ca) & $1 \%$ & $0.02 \%$ & Sodium (Na) & $7.5 \%$ & $<0.01 \%$ \\
\hline $\begin{array}{l}\text { Carbonate } \\
\left(\mathrm{CO}_{3}\right)^{-2}\end{array}$ & $0.5 \%$ & $0.069 \%$ & Sulfur (S) & $4 \%$ & $0.07 \%$ \\
\hline Chromium $(\mathrm{Cr})$ & Nil & $0.002 \%$ & Thorium (Th) & $2.5 \%$ & $0.00006 \%$ \\
\hline Iron $(\mathrm{Fe})$ & $1 \%$ & $<0.01 \%$ & Titanium (Ti) & $0.05 \%$ & $<0.002 \%$ \\
\hline Lead $(\mathrm{Pb})$ & Nil & $0.007 \%$ & Vanadium (V) & $0.3 \%$ & $<0.0001 \%$ \\
\hline $\begin{array}{l}\text { Magnesium } \\
(\mathrm{Mg})\end{array}$ & $0.5 \%$ & Nil & Zirconium (Zr) & $0.1 \%$ & Nil \\
\hline
\end{tabular}

Table (3): A comparison between fixed bed \& dynamic ion exchange technique

\begin{tabular}{lll}
\hline & $\begin{array}{l}\text { Uranium extraction } \\
\text { using Fixed bed method }\end{array}$ & $\begin{array}{l}\text { Uranium extraction } \\
\text { using batch method }\end{array}$ \\
\hline Uranium Conc. & $700 \mathrm{ppm}$ & $700 \mathrm{ppm}$ \\
Mass of resin & $5 \mathrm{grams}$ & 5 grams \\
Volume of the feed solution & $200 \mathrm{ml}$ & $200 \mathrm{ml}$ \\
Flow rate & $1 \mathrm{ml} / \mathrm{min}$. & -- \\
Time & 3 hours and $20 \mathrm{~min}$. & $15 \mathrm{~min}$. \\
$\%$ Extraction & $93 \%$ & $90 \%$ \\
\hline
\end{tabular}

\section{Conclusion}

In this work, high grades of uranium concentrates are produced from the uranium waste solutions. By using batch method, about $90 \%$ of uranium is extracted from ore within 15 minutes. However, fixed bed method extracted $93 \%$ of uranium with longer time by Amberlite IRA400. It is recommended that a significant amount of uranium can be extracted and purified to a large extent from the uranium ore to be used in nuclear activities.

\section{References}

1-C. Ding, W. Cheng, Z. Jin, Y. Sun, Plasma synthesis of $\beta$-cyclodextrin $/ \mathrm{Al}(\mathrm{OH}) 3$ composites as adsorbents for removal of $\mathrm{UO} 22+$ from aqueous solutions, J. Mol. Liq. 207 (2015) 224-230.

2-Weber, C., "Progress in Nuclear Energy", Series 5, vol.2 (1959).

3-V. Stucker, J. Ranville, M. Newman, A. Peacock, J. Cho, K. Hatfield, Evaluation and application of anion exchange resins to measure groundwater uranium flux at a former uranium mill site, Water Res. 45 (2011) 4866-4876.

4-Gasser M.S.,: Adsorption and pre-concentration of Gd (III) and U(VI) from aqueous solution using artificial adsorbents. Separation and Purification Technology 53, 81-88 (2007)53-67

5-Ismail, I.M., Nogami, M. and Suzuki, K., Sep. \& Purf. Techn., 31, 231-239 (2003). 
6- Appelbaum, S. B., "Demineralisation by Ion Exchange", Academic Press, New York, (1968).

7-Kütahyal, C. and Eral, M.,: Selective adsorption of uranium from aqueous solutions using activated carbon prepared from charcoal by chemical activation. Separation and Purification Technology 40, 109-114 (2004).

8-Mohamed S. and Hussein K.,: Using microemulsion for recovery of uranium from phosphoric acid of Annaba (Algeria). Hydrometallurgy 74: 85-91 (2004).

9-Trivedi, U.V., Menon, S.K. and Agrawal, Y.K., React. \& Func. Polym., 50, 205-216 (2002).

10-Boydell, D.W., "Continuous Ion Exchange for Uranium Recovery": An Assessment of the Achievements over the Past Five Years, in Hydrometallurgy '81, Society of Chemical Industry, London, (1981).

11-Cloete, F.L.D., Naden, D. and Streat, M. (Eds.), Proc. SCI Conf., Ion exchange Technology, Ellis Horwood, Chichester (U.K.), (1985).

12-Cloete, F.L.D., "Comparative Engineering and Process Features of Operating Continuous Ion Exchange Plants in South Africa", in Naden, D. and Streat, M. (Eds.), Ion Exchange Technology, Ellis Horwood, London, (1984).

13- Vancouver, B.C. " Kivalliq Announces positive metallurgical results from Lac 50 Trend; Low impurity yellowcake produced" - Kivalliq energy corporation, Jan., 15, (2012).

14-F. Semnani, Z. Asadi, M. Samadfam, H. Sepehrian, Uranium(VI) sorption behavior onto amberlite CG400 anion exchange resin: Effects of $\mathrm{pH}$, contact time, temperature and presence of phosphate, Ann. Nucl. Energy 48 (2012) 21-24.

15-J. W. Clegg and D. D. Foley "Uranium Ore Processing", Addison-Wesley Publishing Co. U.S.A., (1958).

16-X. Zhu, S.D. Alexandratos, Development of a new ion-exchange/coordinating phosphate ligand for the sorption of U(VI) and trivalent ions from phosphoric acid solutions, Chem. Eng. Sci. 127 (2015) 126-132.
17-M. Sprynskyy, T. Kowalkowski, H. Tutu, E.M. Cukrowska, B. Buszewski, Ionic liquid modified diatomite as a new effective adsorbent for uranium ions removal from aqueous solution, Colloids Surf., A 465 (2015) 159-167.

18-R. E. Treybal, Hand Book of "Mass Transfer Operations", $3^{\text {rd }}$ edition, McGraw-Hill Book Co., New York (1984).

19- M.E.Sheta; Extraction of Uranium from Sulfuric acid Solution, Ninth Conference, Arab Atomic Energy Agency, Sudan, (2012).

20-Mahmoud, K.F., 2003. Simulated heap leaching studies of Qattar uranium occurrences. Int. Rep. NMA, Cairo.

21-Marczenko Z. Spectrophotometric Determination of Elements. New York: John Wiley and Sons, 1986, 107-640

22-Martell, R. M., \& Smith, A. E. (1976). Critical stability constants. New York: Plenum Press.

23- Inczedy, J. (1976). Analytical applications of complex equilibria. Chichester: E. Horwood.

24-Anderson, R. E., Bauman, W. C., \& Harrington, D. F. (1955). Sulfate-bisulfate equilibrium on anion exchange resins. Ind. Eng. Chem., 47, 1620-1623.

25- Bożena Danko et al "Ion exchange investigation for recovery of uranium from acidic pregnant leach solutions".NUKLEONIKA 2017;62(3):213221 doi: 10.1515/nuka-2017-0031

26-Copelwitz, and B.K. Loveday, "An analysis of continuous resin contacting. Hydrometallurgy, 4, 259-268 (1979).

27-M.J. Slater, "Continuous ion exchange plant design methods and problems. Hydrometallurgy, 4, 299-316 (1979).

28-Vancouver, B.C. " Kivalliq Announces positive metallurgical results from Lac 50 Trend; Low impurity yellowcake produced" - Kivalliq energy corporation, Jan., 15, (2012). 